\title{
Criteria for choice in Research and Development Evaluation in Sri Lanka
}

\author{
R. P. JAYEWARDENL \\ Director-General, Natural Resources, Energy \& Sciense Authorty of Sri Lanka. \\ 47/5, Maitland Place, Colombo 7, Siri Lanka.
}

\section{Criteria for choice in $R$ \& D Evaluation in Sri Lanka}

The evolution of the concept of choice has taken many ywars. In the early years the choice of a subject for research was an individual's own intellectual curiosity. The reputation of the scientist depending on the merit of his research work soon became the consideration for financial support from academic and scientific societies. Later it became necessary to seek government funds for science and technology research. With the increasing demand for such funds the concept of choice became necessary with emphasis on the systematic usc of scientific knowledge to attain definite economic and social goals.

The criteria for choice then became necessary. The criteria must be defined, understood, and whenever possible, readily applicab. the selection of research proposals.

Choices have to be made to ensure a fair and equitable distribution of limited $\mathbb{R}$ \& $D$ funds between the various (1) fields of science, (2) institutions.

Withn the field of science we accept two categories (1) Basic science, (2) Applied science. Although in many areas the distinction between the two is not always clear it is a useful guide in the selection process.

In the developing countries, it is imperative to distribute limited resources to areas of scientific research which help in the development process. Hence science for development - becomes the most important criterion for choice. Basic science will therefore take a second place. As it is often academic, research in this field will be more or less confined to the universities.

The next criterion will be the necessity 're research training for scientists. The shortage of scientific manpower hampers th. "esearch effort and the development of the country. Therefore, a research proposal should aim at training one or more assistants in research methodology leading to a masters or doctorate degree. In Sri Lanka, we have adopted a policy where science for development and research training are the important criteria in the selection process. 
The Natural Resources, Energy and Science Authority attempts to achieve this by establishing a "peer review" mechanism to evaluate project proposals and to monitor and assess the research work done on the grants awarded from time to time.

Working Committees - There are ten working Committees to cover the fields - Natural Resources, Energy, Physical and Engineering Sciences, Chemical Sciences, Biological Sciences, Medical and Veterinary Sciences, Agriculture and Animal Husbandry, Science Education, Science Information, Social Sciences.

The members of these Committees are senior experts in their fields of research. In addition, one or two members from a related field are included. This ensures the elimination of a narrow parochial viewpoint so that a research proposal may be judged from a larger perspective of its relevance to the rest of science.

Research Grants Scheme - Research proposals are invited through the national newspapers about the middle of each year and the awards are made by December so that work may commence in January of each year.

The major beneficiaries of this scheme are the Universities. Since research in the Universities is not related to any specific national programme, but is largeiy the outcome of self-motivation, rather flexible criteria have been set out for selection of projects.

Evaluation of projects - The criteria may be summarized as follows:

1. Relevance to short-term national development;

2. Contribution to the stimulation of university teaching as a means of achieving broad based, long-term, national development;

3. Multidisciplinary nature, particularly in respect of important national problems requiring scientific collaboration of several public sector institutions;

4. Uniqueness arising out of conditions special to Sri Lanka;

5. The availability of a suitable supervisor in the case of young applicants with little or no research experience.

6. Possibility of obtaining a research degree (M.Sc., Ph.D., M.D.) as the basis of research carried out in Sri Lanka;

7. Re-orientation of scientists who have returned after protracted stays abroad;

8. Previous research carried out locally, and the performance with research grants awarded by the former National Science Council or Natural Resources, Energy \& Science Authority (NARESA). 
Monitoring of research projects - Monitoring of programmes of research in all research organizations and sponsoring agencies, is through periodic progress reports. NARESA requests half-yearly and final reports.

Criteria for assessment of progress reports are again flexible. The Working Combrittees generally look for evidence in respect of quantity and quality of work performed within the period under review in relation to the total volume of work expected to be carried out within a programmed time scale.

Majority of the projects supported by NARESA are exploratory in nature, and not specifically problem-oriented. Hence each project in effect is only a phase in the study of a bigger field of investigation. Although research sponsorship has to be considered an investment in projects of this nature (the research output) could hardly be quantified in clear monetary terms. Therefore unlike problem-oriented research programmes, or projects which carry an element of commercial or national profitability, these research activities are not amenable to evaluation procedures such as the social cost-benefit analysis.

When scientific research in any form is financed and carried out by a research institution, the net benefits can sometimes be evaluated as the "Net Added Value" to the institution. However, when a sponsoring agency such as NARESA or any other research council funds a programme of research, the net gains are not fully enjoyed by the sponsoring agency. In such cases the gains are distributed among the principal investigator, his research assistants, and the institution in which such research work was carried out. However, if the sponsoring agency is a state institution, then the total value added is a national gain, and hence may be assessed in the context of national profitability. 